\title{
Ethnobotanical Research in Homegardens of Small Farmers in the Alpine Region of Osttirol (Austria): Photo Essay
}

\author{
Brigitte Vogl-Lukasser \& Christian R. Vogl
}

\begin{abstract}
Photo Essay
Today, almost every household in Eastern Tyrol owns at least one camera. Photography is mainly used to document special events such as family festivities or the development of one's children. Everyday work, especially that of women farmers, common landscape scenes, or "unspectacular" plants are hardly found in the photo collections of local people. These neglected topics are not only missed in the photo collections, but often also lack a space in people's minds.
\end{abstract}

As we started with our research on homegardens in Eastern Tyrol, one of our first questions asked of local experts of different professions, ages and gender, was: Where can we find home gardens in Eastern Tyrol? The most common answers were:

- "I don't know."

- "I think, there are no home gardens in the region any more".

- $\quad$ "I think in former times home gardens were widespread throughout the region and they were very beautiful. But now?"

It is fascinating for us that the complete opposite of these opinions was found to be true as a result of our research. Photography was an important tool and method in our research and we shall now explain how we used it.

\section{The Social Context}

Ethnobotanists not only look at gardens, plants and landscapes but at the interactions of people and plants. Therefore it is necessary to learn of these interactions. One can ask people about them or one can participate in the interactions. That is what we did. Moreover, we also documented interactions by taking photos. These pictures not only serve documentation purposes or act solely as a mental anchor between the interviewer and the garden, but may be used in interviews to elicit information about what can be seen on these pictures.

To shoot pictures of landscapes, gardens or plants is different from taking photos of human beings. To ask for permission to take a photo of the garden or the plants in the garden is usually not a problem for interviewers. Asking permission to take pictures of people when they are working in, or simply enjoying, their gardens is different, and we learned that most interviewers who we had hired as support for our survey felt uncomfortable making this request.

Obviously one needs a good social relationship with the respondents in order to obtain a consenting answer, however, we learned that in most cases the question posed more of a problem for the interviewers than for the respondents. We felt that "shy" interviewers, or interviewers unfamiliar with taking pictures in these situations, had to be made aware of the significance of taking and having pictures. A full explanation of this issue and a careful training of interviewers on "How to ask for

\section{Correspondence}

Brigitte Vogl-Lukasser \& Christian R. Vogl, Arbeitsgruppe Wissenssysteme und Innovationen, Institut fuer Oekologischen Landbau, am Department für nachhaltige Agra rsysteme,Universitaet fuer Bodenkultur, Gregor Mendel Strasse 33, A-1180 Wien, AUSTRIA. bvogl@edv1.boku. ac.at, vogl@edv1.boku.ac.at

Ethnobotany Research \& Applications 3:079-097 (2005) 
permission" and "How to take really good pictures" was very important.

Although ethnobotanists would like to have photos from interviewees' every day life this is not always possible. Often we had to respect the fact, that the interviewee wanted "to get prepared" for the photo session (to comb her hair; to put on a nice dress; to get rid of the scarf and old rubber boots; ...). As a consequence pictures with people, who prepared themselves for the picture taking session, lost their "natural setting". Nevertheless in these occasions we learned:

1. what people consider to be "beautiful",

2. where they have their favourite places, and

3. which actions they believe to be representative of their activities in gardens.

In order to get really good photos from interviewees at work or at leisure in gardens, extra tours specially dedicated to taking pictures, were undertaken. As gardeners do work nearly every day in the gardens, one has to know just when they usually do this work during the day. When we came unannounced and explained the need for documenting every day life in gardens we usually succeeded in taking pictures of these occasions.

We also took photos of our working process and the methods and tools used, e.g. one scientist took photos of the other scientist during his/her work (interviewing, taking specimens, taking photos, etc.). These pictures were very useful:

1. to assess problems and characteristics of the social interaction of the interviewers and the interviewees,

2. in the training of other scientists and

3. for methodological lectures.

\section{Technicalities}

We took all our pictures that are published here between 1996 and 1999 with a Minolta Dynax 600 Si Classics analog camera, in most cases using a zoom lense of 28 $-105 \mathrm{~mm}$, a polarisation filter and 100 or 200 ASA Kodak Extrachrome slide film. Taking photos was done "learning by doing" with a meticulous assessment of the pictures taken as soon as they were developed. We often pulled the trigger from different angles and with different camera settings. Our "consumption" of slide film was substantial, but fortunately we had the budget for it. We archived only about $20 \%$ of the pictures taken and threw the rest away. The elimination of pictures of bad quality (out of focus, miserable content, unattractive colors, without any information, etc.) was essential to control our slide load and had to be done very rigorously.

Only selected slides were scanned with professional rotation scanners creating *tif.-formatted pictures of 20 $25 \mathrm{MB}$ per picture. These files were used for a book
(Vogl-Lukasser 2003) and were also downsized for other purposes (lectures, papers, flyers).

We now also own digital cameras but using them and how digital pictures compare to slides are different and highly controversial topics which we do not want to address here.

\section{Our topic of research}

Parallel to our increasing ethnobotanical knowledge about our topic of research, different photos relating to different topics were taken:

- At the beginning and during work photos were used to document gardens in general and unknown species in particular;

- $\quad$ During work we learned about new practical issues of our research (e.g., about the variety of sources of seeds and plantlets), this came as a surprise to us. We checked if we had pictures of these elements already, and if not we added them to a list of "pictures to be taken" (e.g., take picture of a farmer buying seeds in the supermarket of the district capital);

- During further research new hypothesis and theoretical topics arose, which we wanted to make visible. We searched for motives that might represent and make these topics visible and took pictures of them;

- Finally, once we were confident that we had what we needed to document our work, we felt more and more comfortable to follow a more creative approach, taking pictures, which might be seen as artwork.

\section{How did/do we use photos?}

We found photos very helpful for many different tasks and aims during our research. These were/are:

- As an evidence of plant species found, complementary to herbarium specimens;

- As an evidence of plant species found for those species with extremely low abundance (where no herbarium specimens could be taken);

- For the documentation of traditional tools, items and structures (used) in gardens; and for their later characterisation in case that neither we nor respondents could explain their origin, composition or purpose;

- For the documentation of social activities in gardens between gardeners, family members or passers by;

- For the documentation of important cultural events and customs with relation to gardening;

- As a present for respondents;

- As a means to communicate with respondents, other local people, the scientific community, students, friends and others about gardening and gardens;

- As a means to make our methods visible; 
- $\quad$ As a means to make reports and publications more attractive. Reports or project proposals with pictures help to visualise topics and to attract interest;

- As a means of marketing results and the importance of the topic, e.g. for policy makers. Thus we developed and printed colour flyers (two pages with 8 colour pictures and the essential conclusions of the project);

- For presentations in Power Point in the classroom or at conferences;

- For meetings and events with local people, where we gave slide shows as a means to present the results of our mutual work to them, and with the same motivation we made a book (Vogl-Lukasser 2003).

\section{Summary}

To be able to give ethnobotanical information back to a broad audience in an appealing way, using pictures as a means to visualise methods and results, has been highly important for the local, regional, national and international impact of our research. Words of recommendation: Take enough time and sufficient equipment to take really good pictures and films of the interaction of people and plants!

\section{Literature Cited}

Vogl-Lukasser, B. 2003. Über'n Zaun g'schaut Osttiroler Bäuerinnen und ihre Gärten. Verbandes der Tiroler Obst- und Gartenbauvereine Tirols / Grünes Tirol, Innsbruck, Austria, ISBN3-9501756-0-1. To be ordered for $25 €+$ postage at the authors address (see box).

Vogl-Lukasser, B. \& Christian R. Vogl. 2004. Ethnobotanical Research in Homegardens of Small Farmers In the Alpine Region of Osttirol (Austria): An example for bridges built and building bridges. Ethnobotany Research and Applications 2:111-137. 


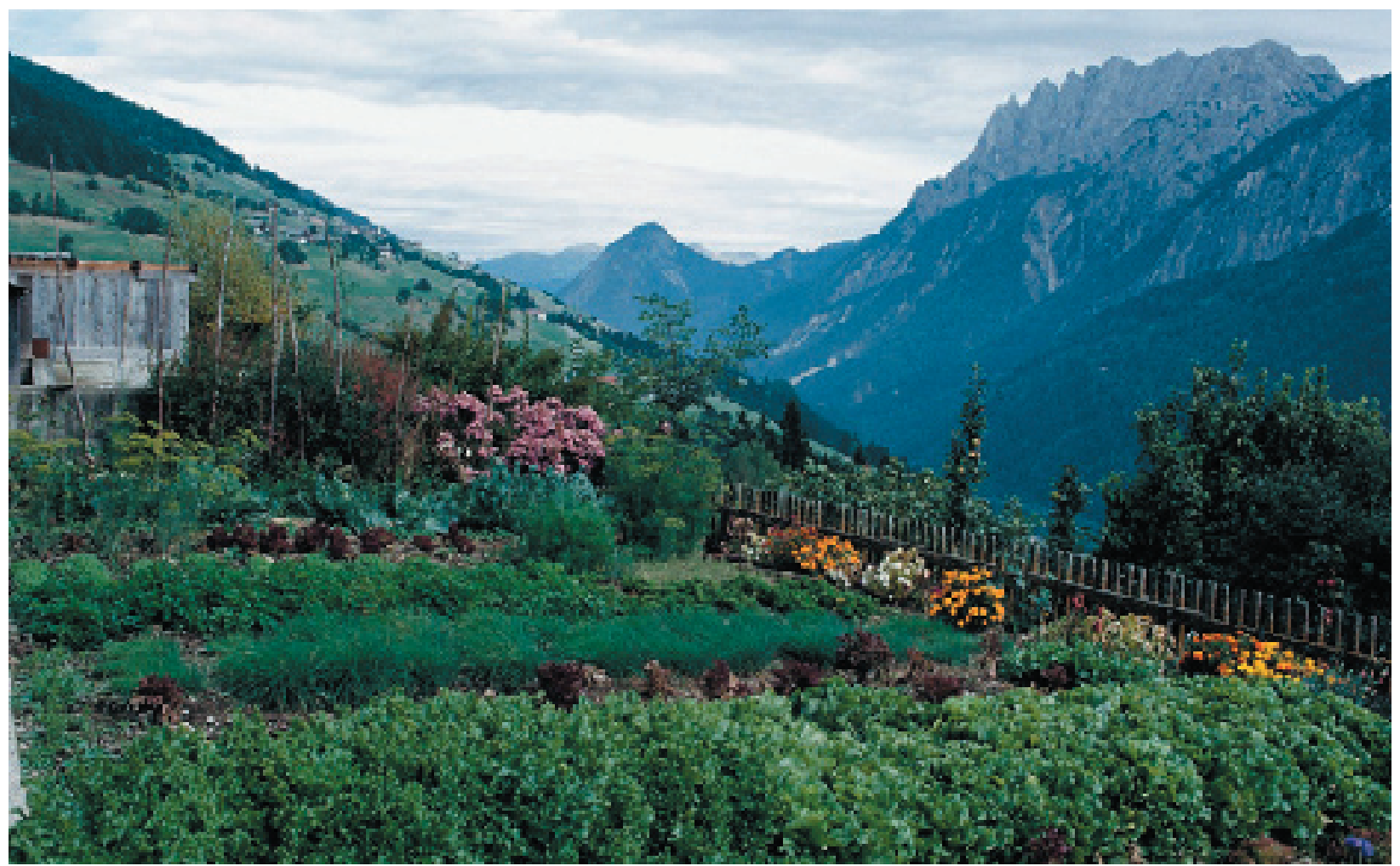

Above: Homegarden in Assling (Eastern Tyrol, Austria) with the Lienz Dolomites in the back (B.Vogl-Lukasser).

Below: Homegarden in Assling (Eastern Tyrol, Austria) with home made green house in front of the barn (B.VoglLukasser).

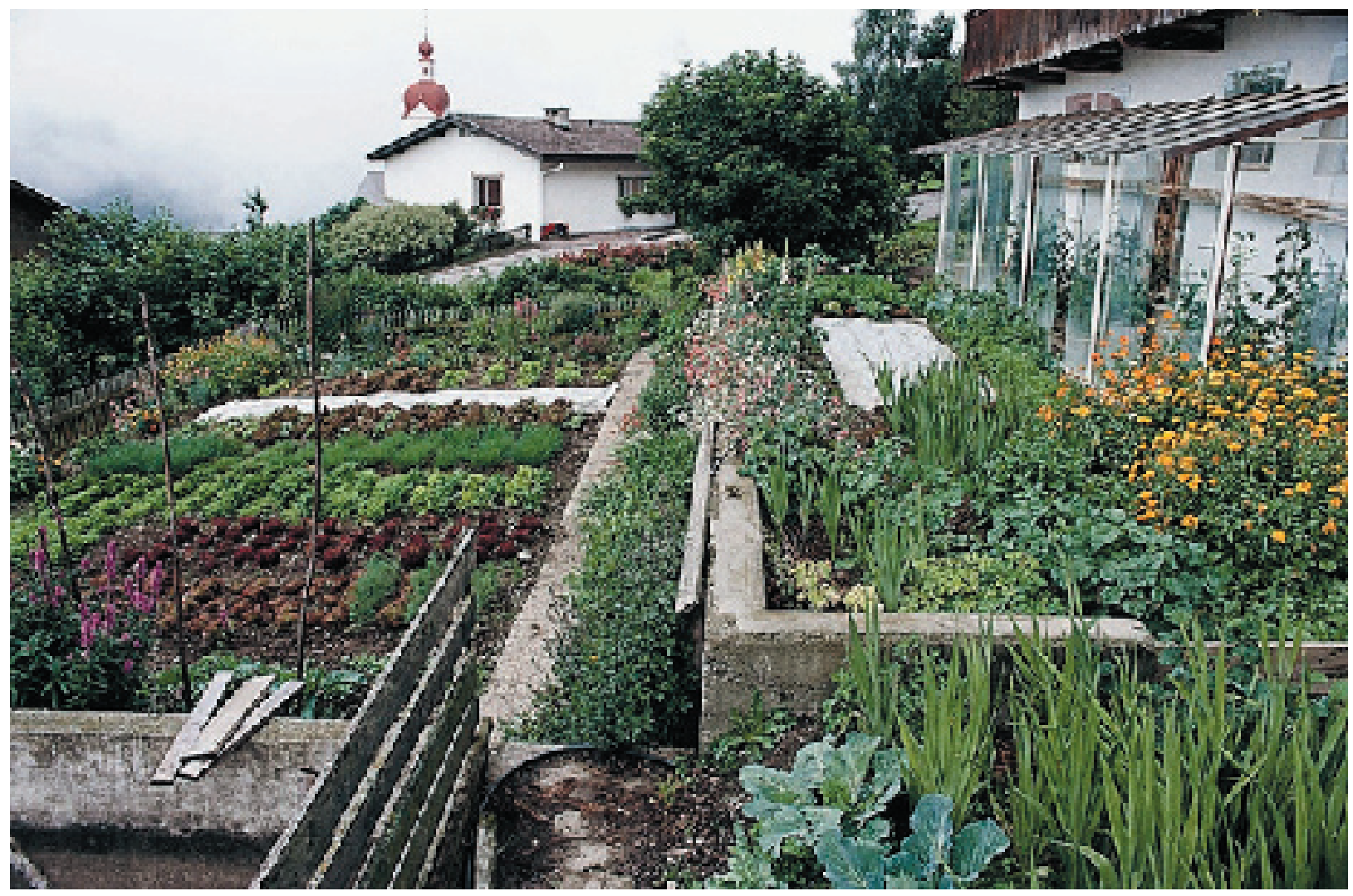

www.ethnobotanyjournal.org/vol3/i1547-3465-03-079.pdf 


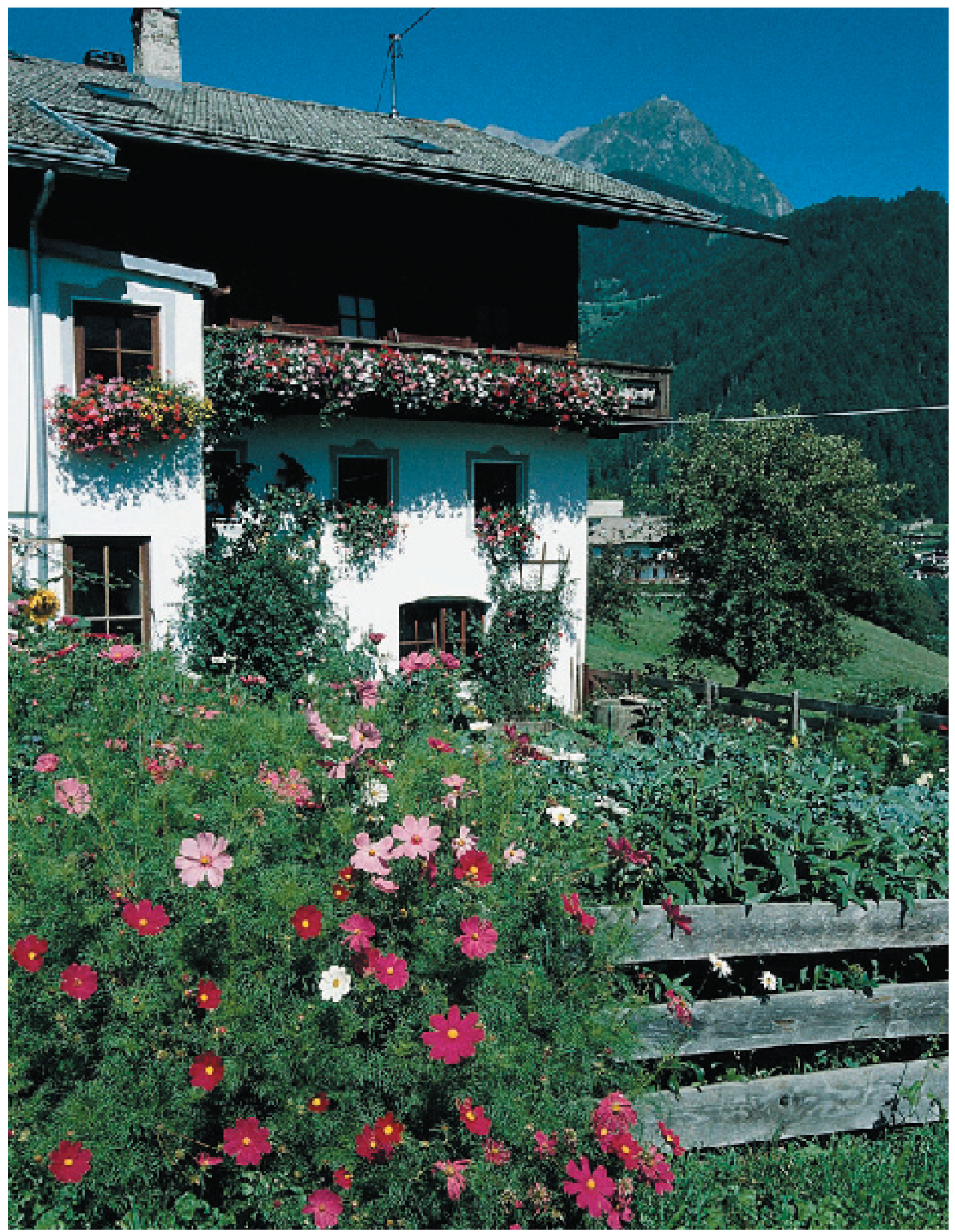

Above: Homegarden and living house of farmers in Matrei (Eastern Tyrol, Austria) (B. Vogl-Lukasser). 


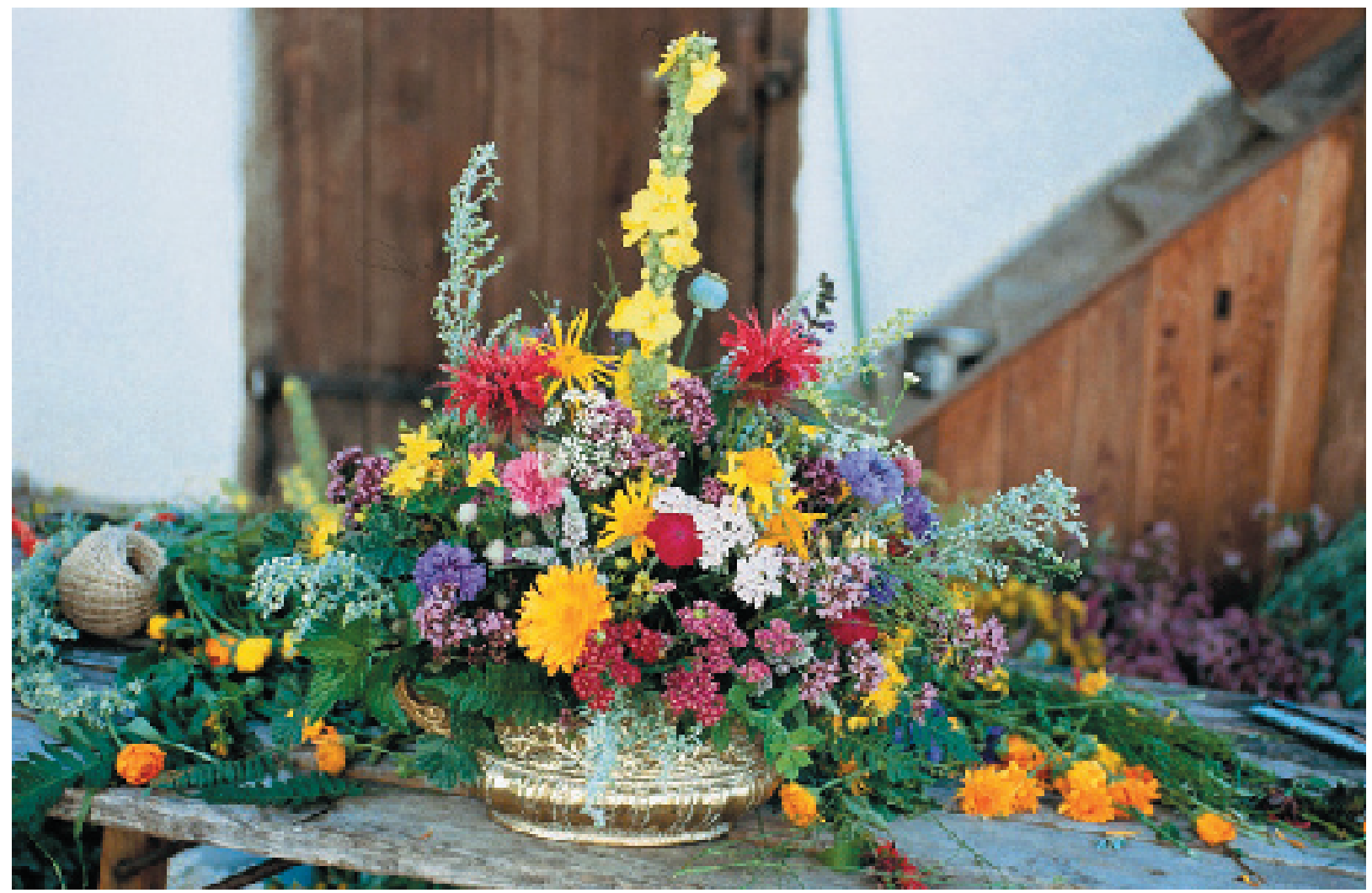

Above: A bouqet of beautiful flowers which all have medicinal use, made by a women farmer for a catholic holiday in August in Gaimberg (Eastern Tyrol, Austria) (B. Vogl-Lukasser).

Below: Woman gardener in Gaimberg (Eastern Tyrol, Austria) irrigating with a watering can with water from a barell (right, back). The slighthly warm water from the barell (in comparison to cold water from the tube) ensures better growth of young plantlets (B. Vogl-Lukasser).

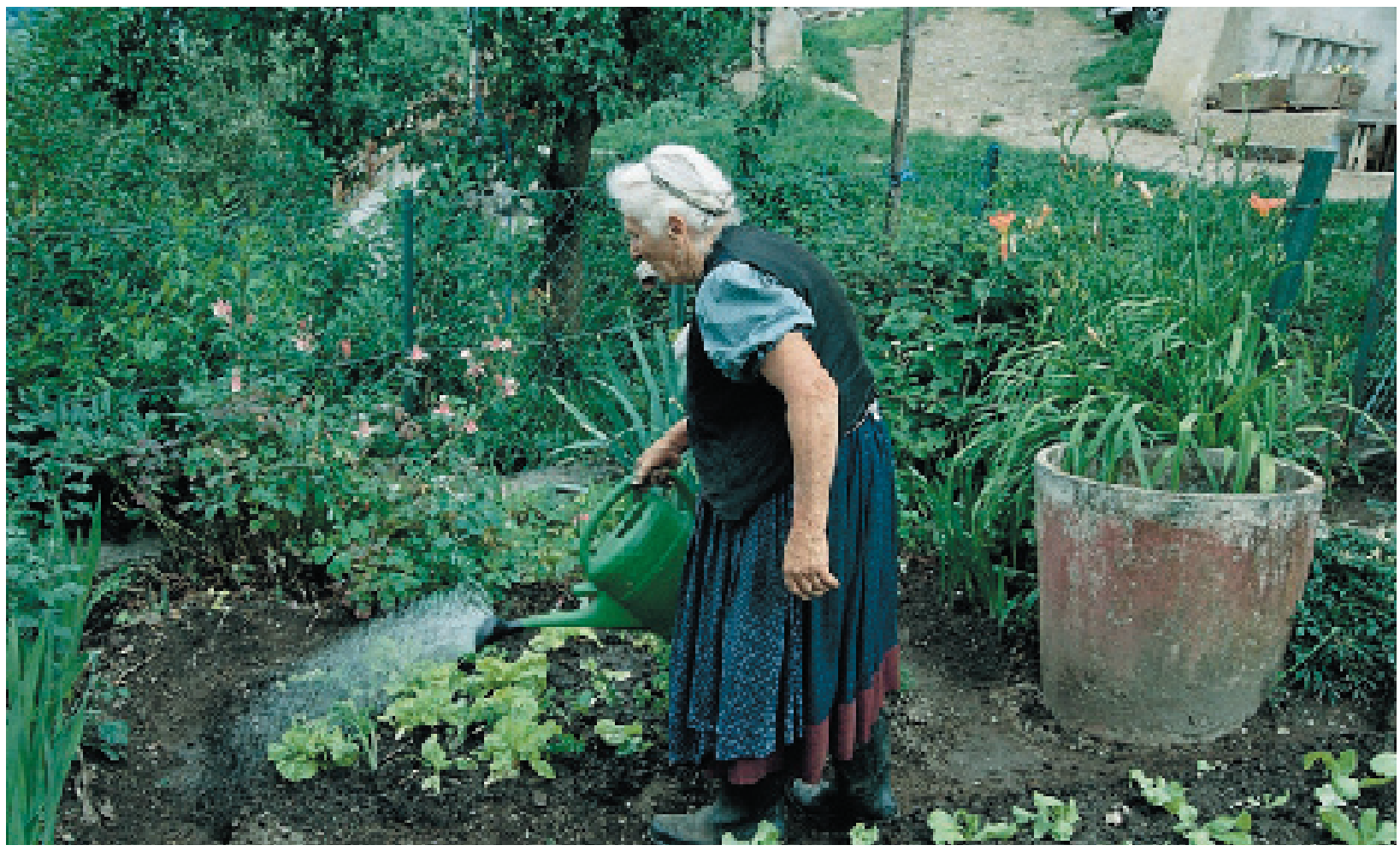




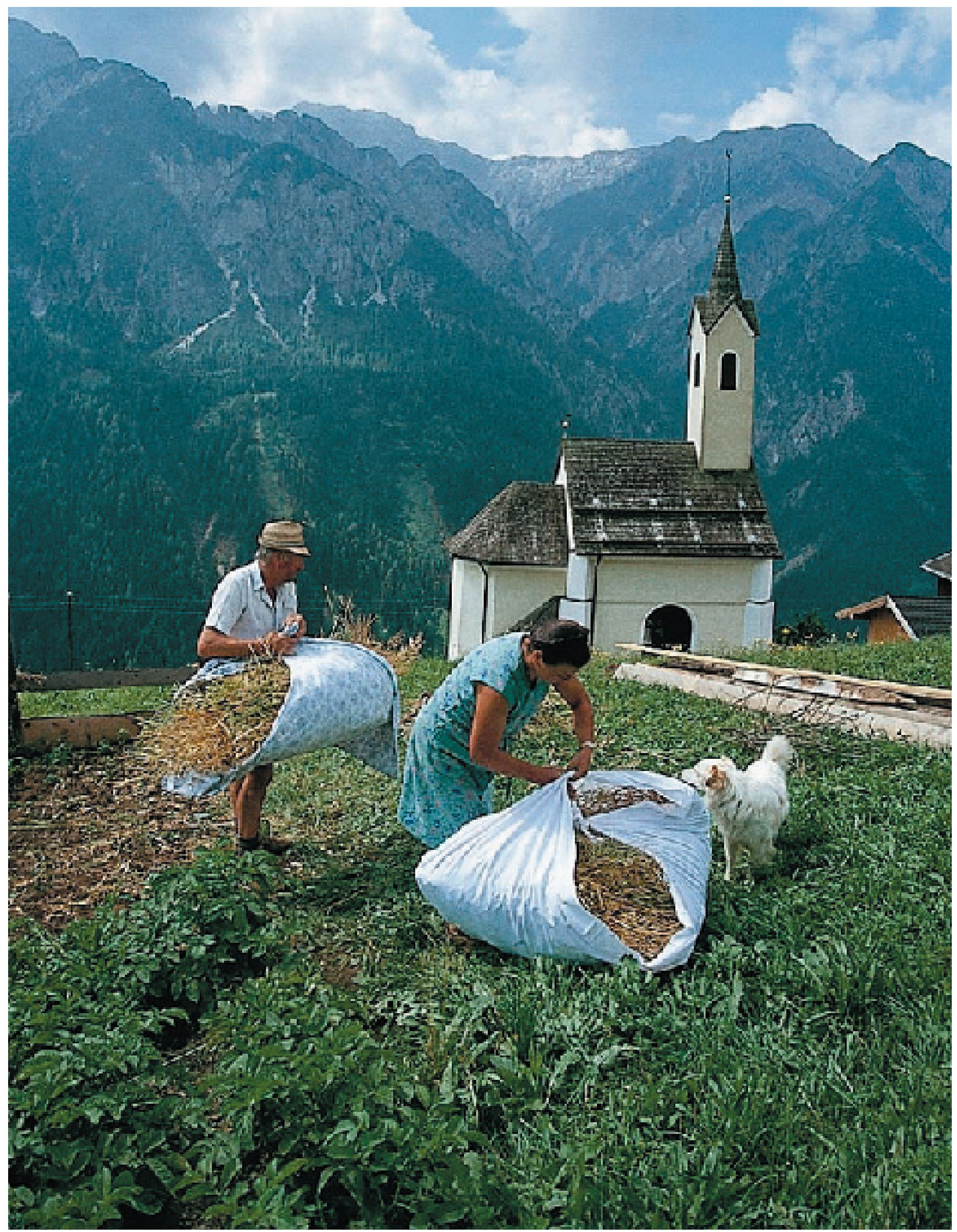

Above: In Assling (1,200 m; Eastern Tyrol, Austria) plants of biannual Brassica rapa ssp. rapa (turnip) are harvested for later drying and threshing in the barn. Seeds are sown the next year to grow turnip and to produce lactic acid fermentated turnips (Ruebenkraut) (B. Vogl-Lukasser). 


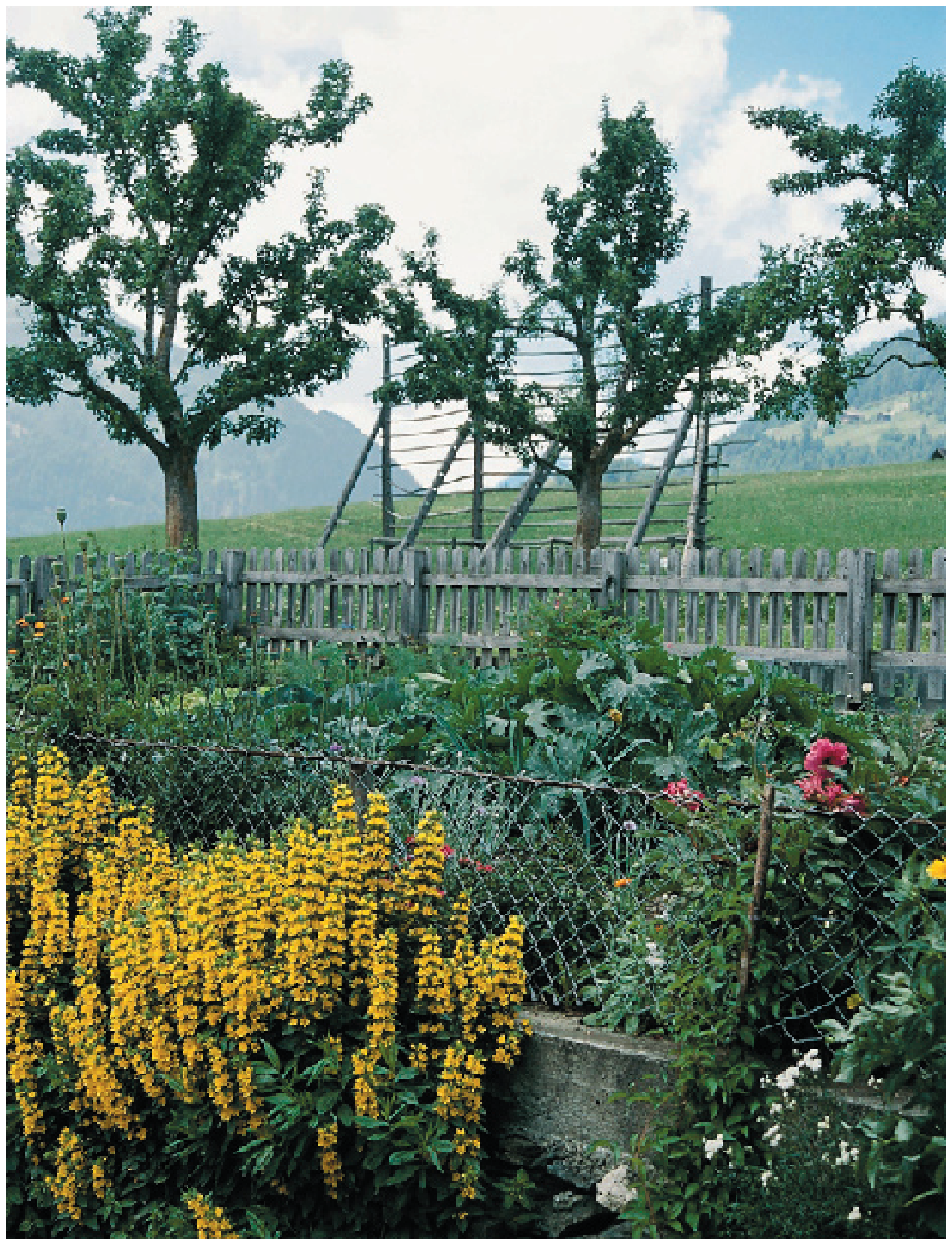

Above: Homegarden in Virgen (Eastern Tyrol, Austria). In the back: Apple trees and a lattice used until the 1960s to dry cereals in the open air (B. Vogl-Lukasser). 


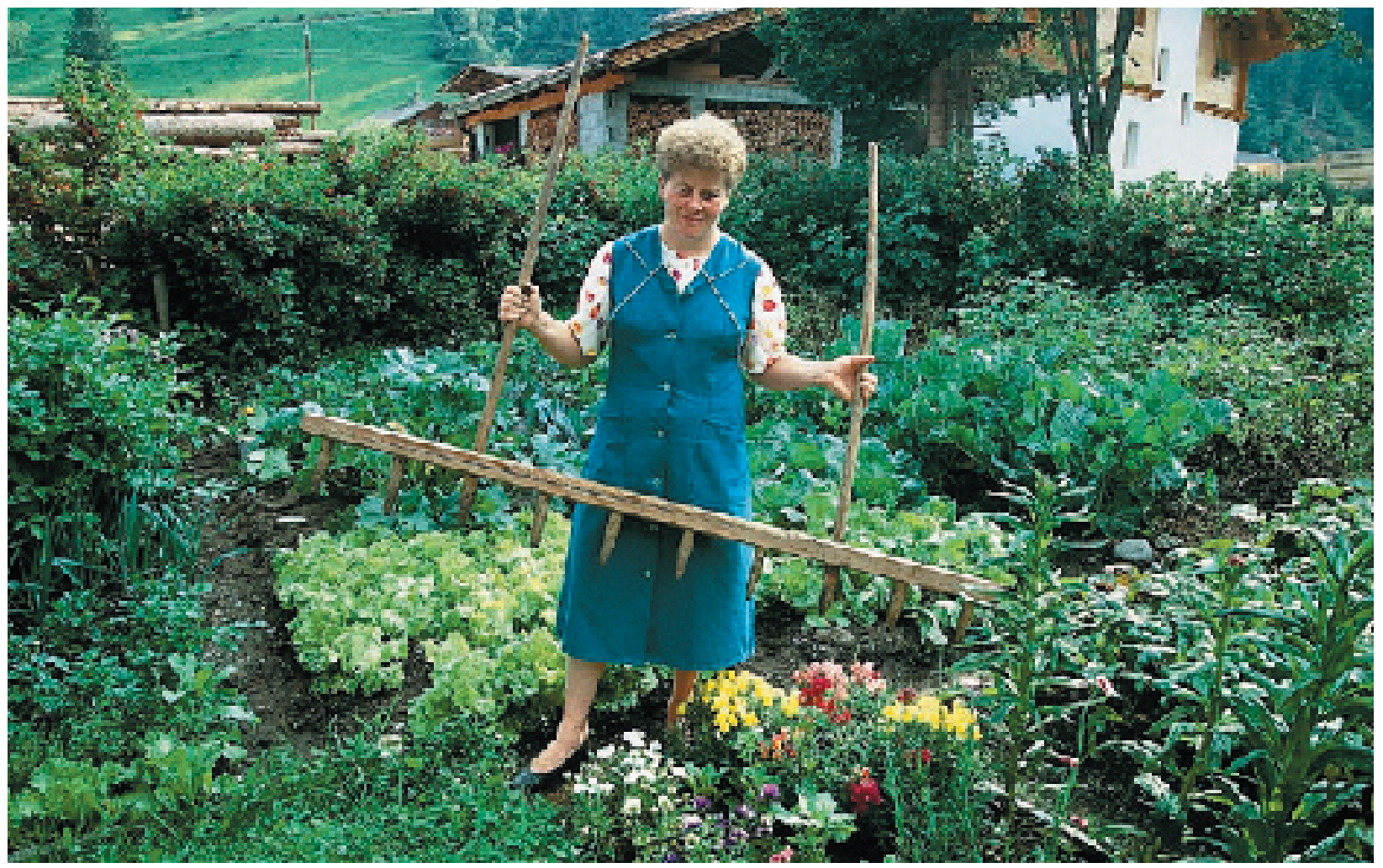

Above: Woman farmer in Innervillgraten (Eastern Tyrol, Austria) with a traditional tool that is used to make holes for sowing beans (Vicia faba) or other crops with larger seeds (B. Vogl-Lukasser).

Below: Woman gardener in Sillian (Eastern Tyrol, Austria) turning over the soil to prepare the garden for sowing/ planting (B. Vogl-Lukasser).

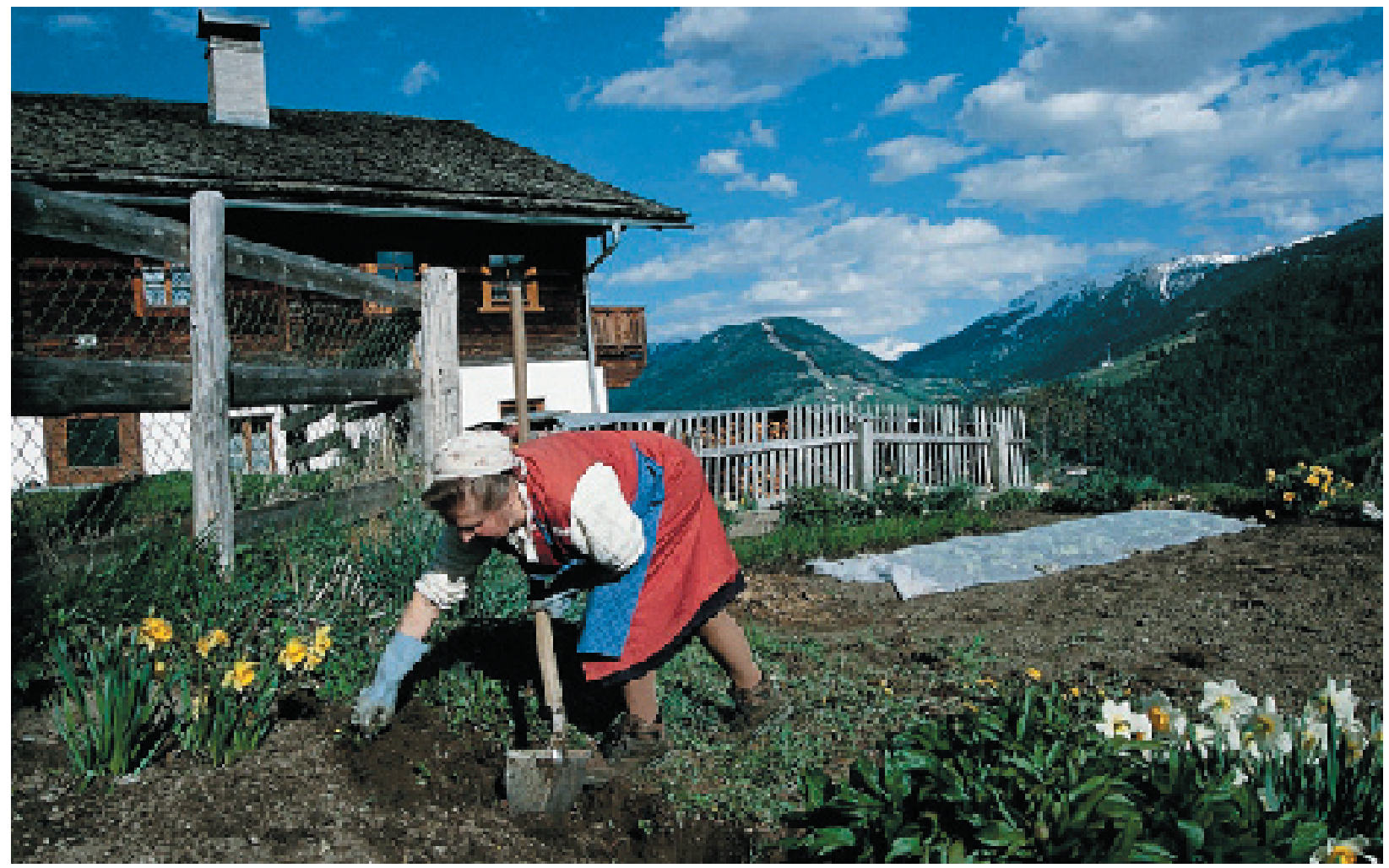




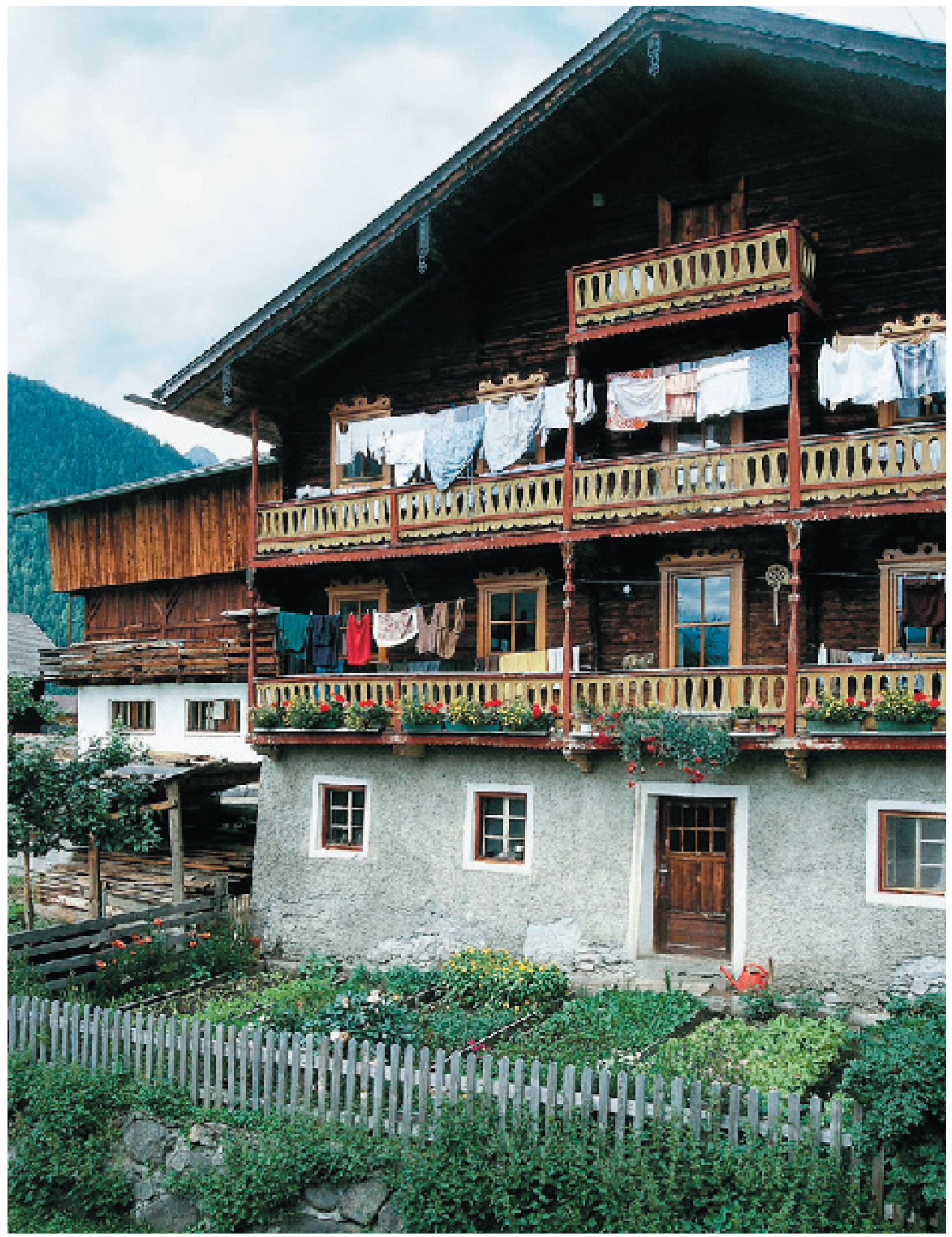

Above: Homegarden and living house of farmers in Kals (Eastern Tyrol, Austria) (B. Vogl-Lukasser). 


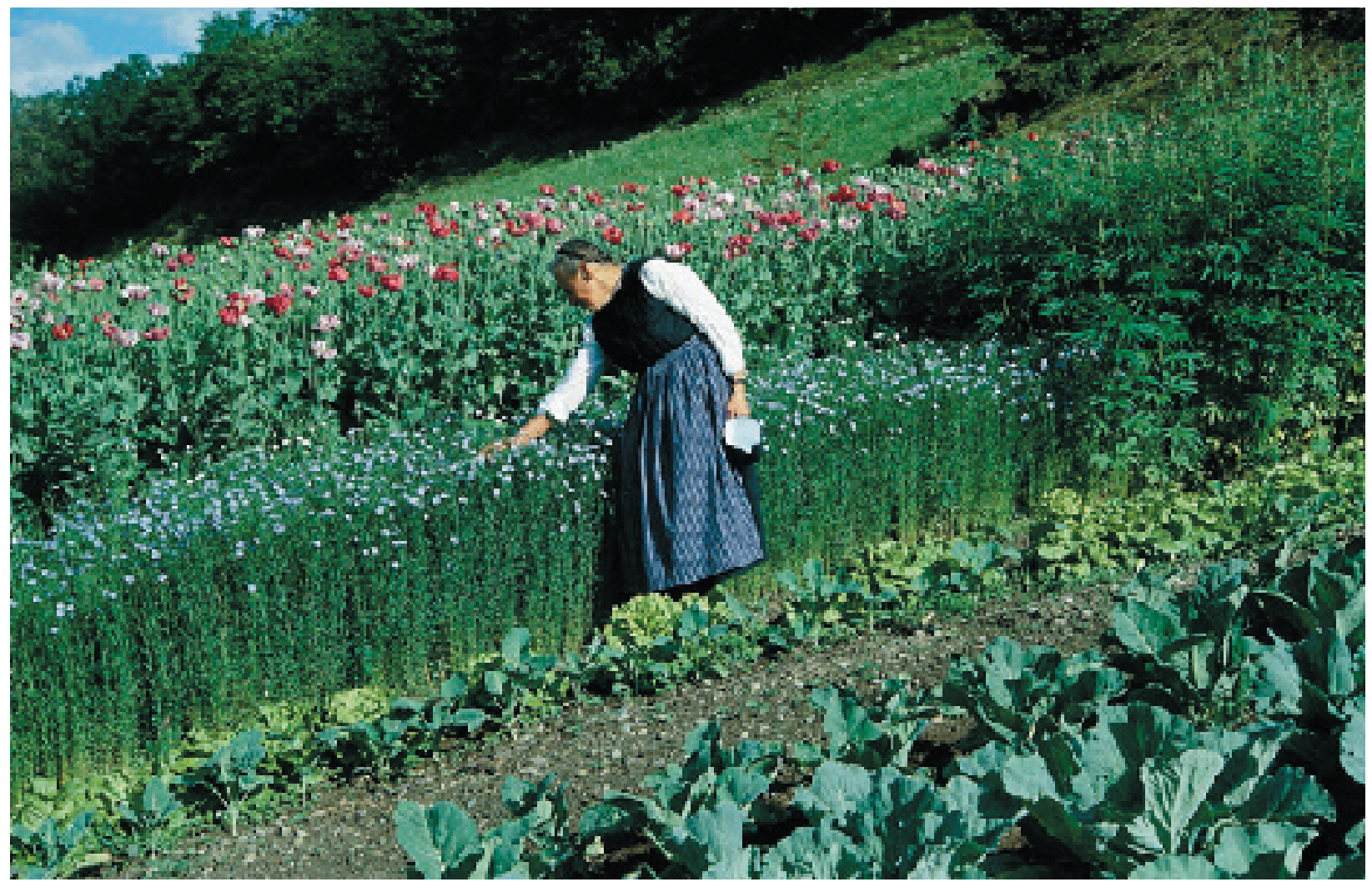

Above: Elder woman farmer in Zedlach/Matrei (Eastern Tyrol, Austria) at her field plot with the traditional regional crops Papaver somniferum, Cannabis sativa, Linum usitatissimum and different vegetables (B. Vogl-Lukasser).

Below: Woman gardener in Assling (Eastern Tyrol, Austria) harvesting Lepidium sativum. The mountain range of the Lienz Dolomites is in the back (looking East) (B. Vogl-Lukasser).

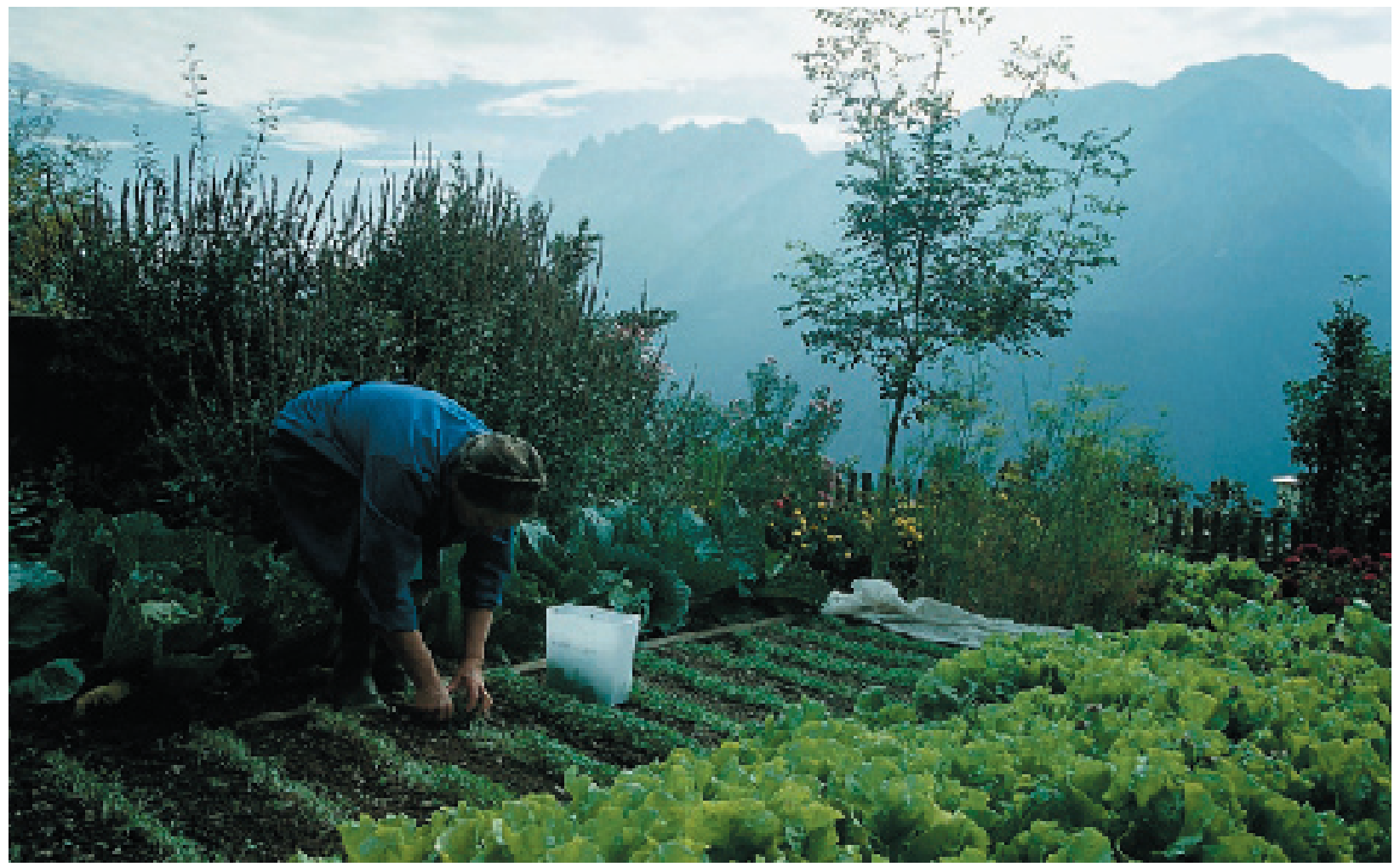

www.ethnobotanyjournal.org/vol3/i1547-3465-03-079.pdf 


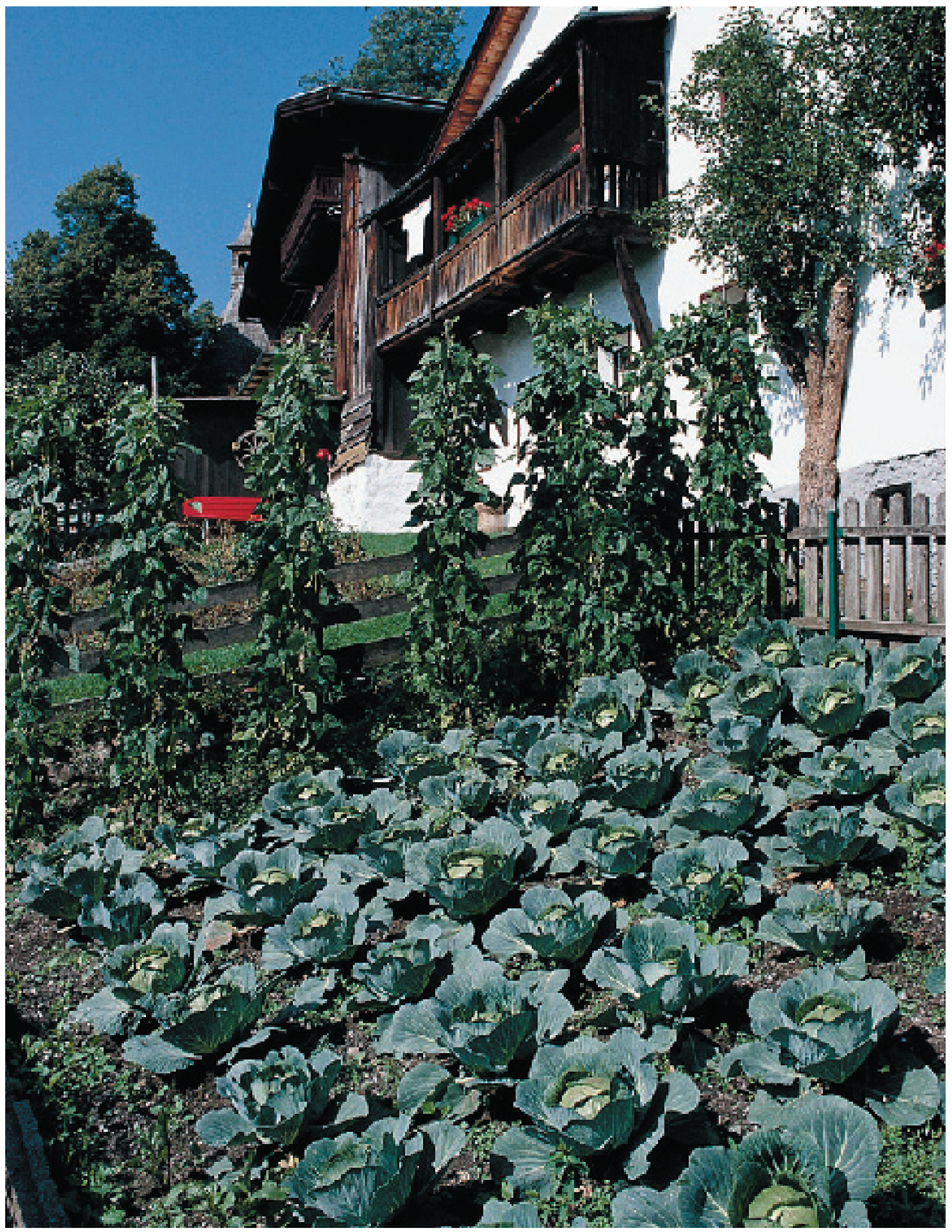

Above: Homegarden, barn and living house of farmers in Assling (Eastern Tyrol, Austria). Many field vegetables and arable crops, grown in the fields until the 60ties, are now grown in gardens such as this one with beans and cabbage (B. Vogl-Lukasser). 


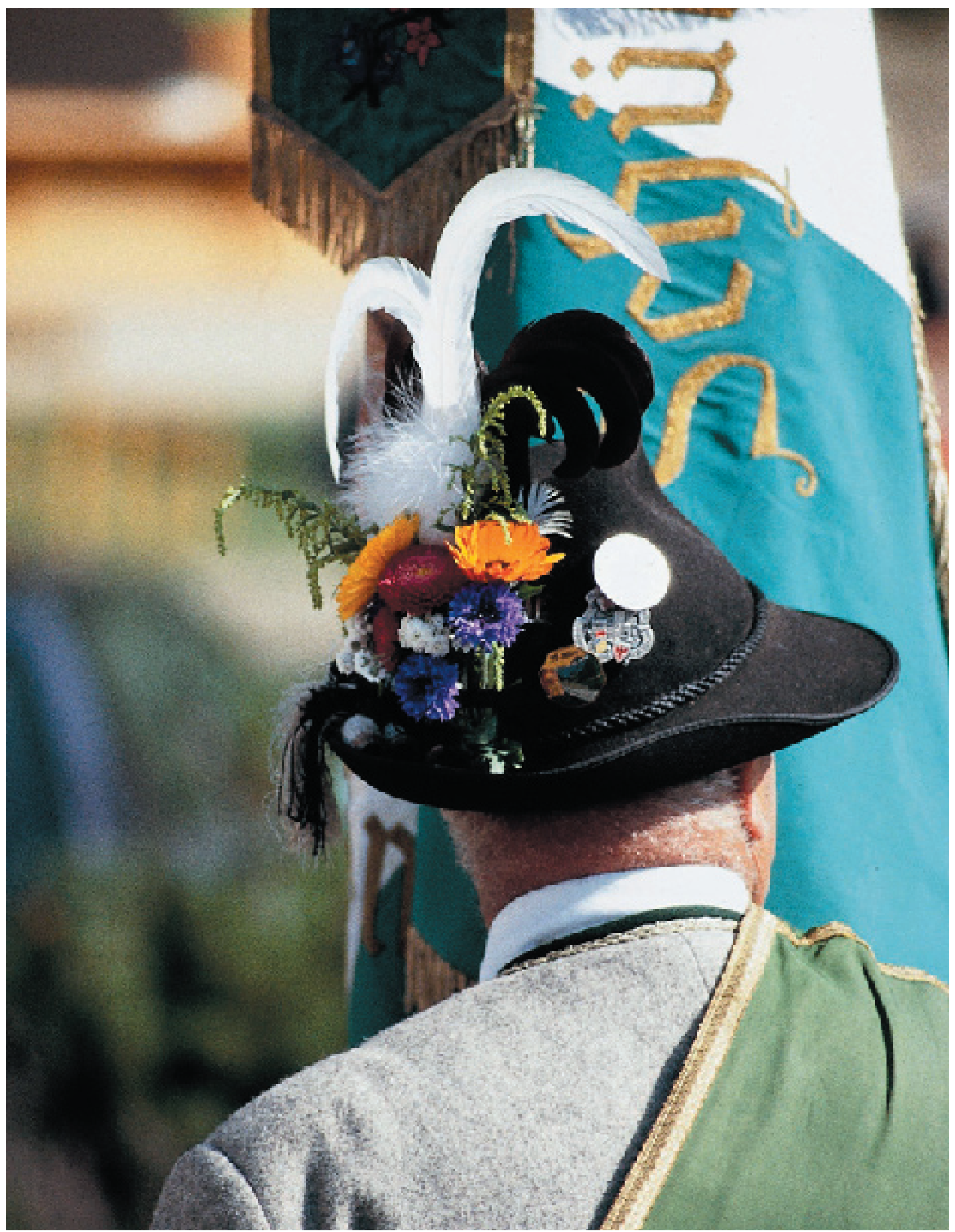

Above: During traditional festivities, where the local brass band performs, or where the local civil defence unit presents, hats are decorated with flowers from the garden (B. Vogl-Lukasser, Assling, Eastern Tyrol, Austria). 


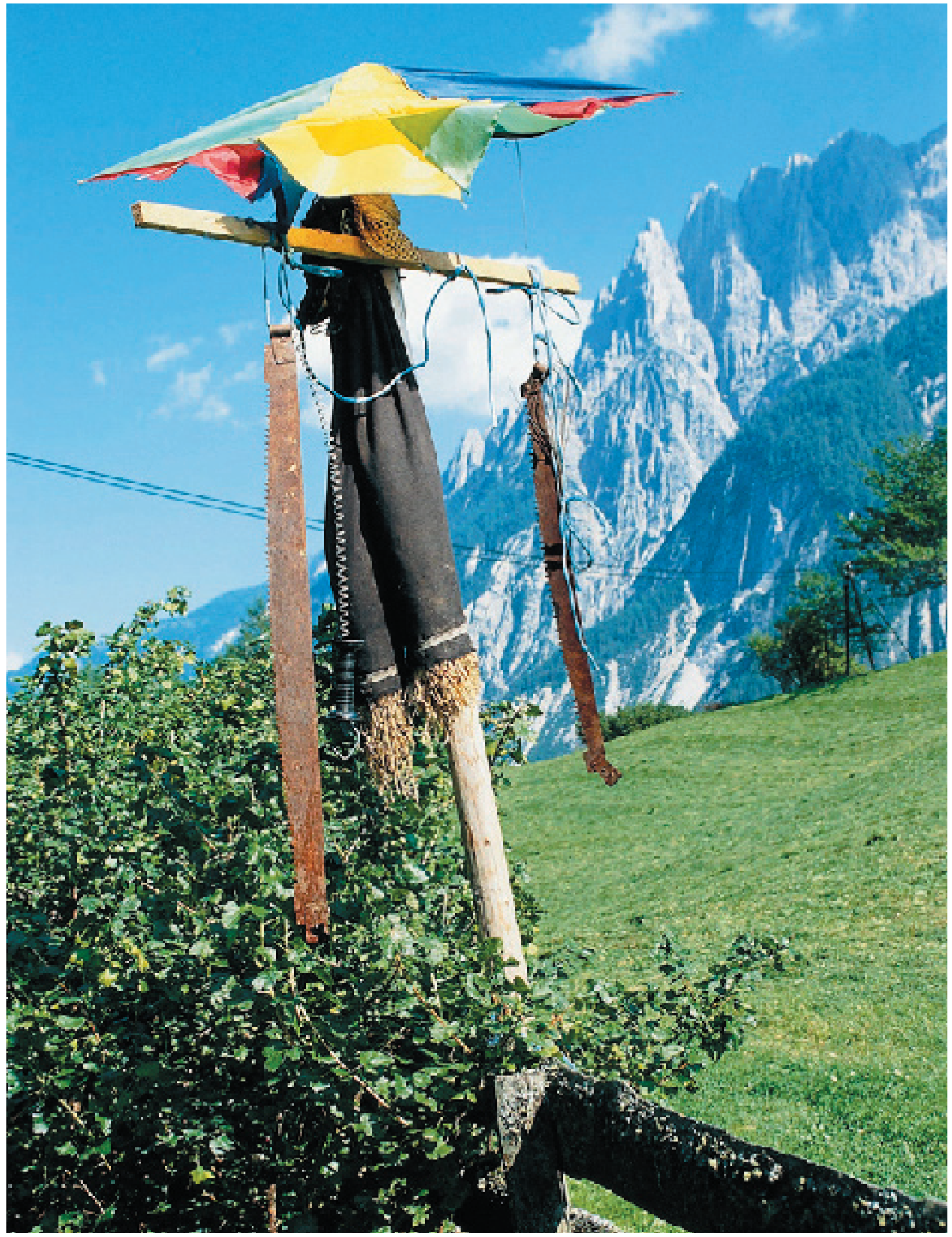

Above: Home made scare crow fixed at a garden's fence in Assling (Eastern Tyrol, Austria) (B. Vogl-Lukasser). 


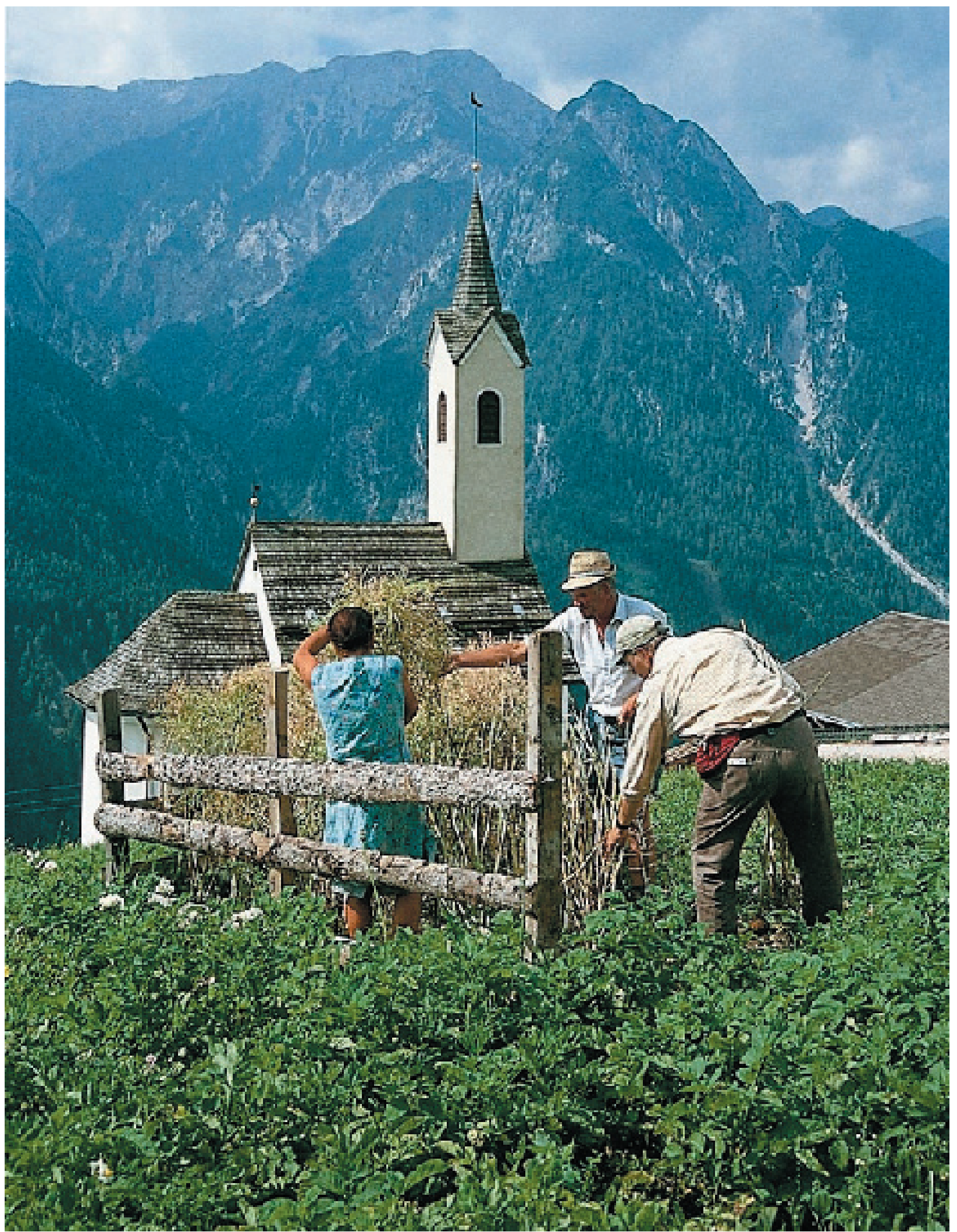

Above: In Assling (1,200 m; Eastern Tyrol, Austria) biannual Brassica rapa ssp. rapa is grown in its second year in protected little "gardens" for the production of seeds (B. Vogl-Lukasser). 


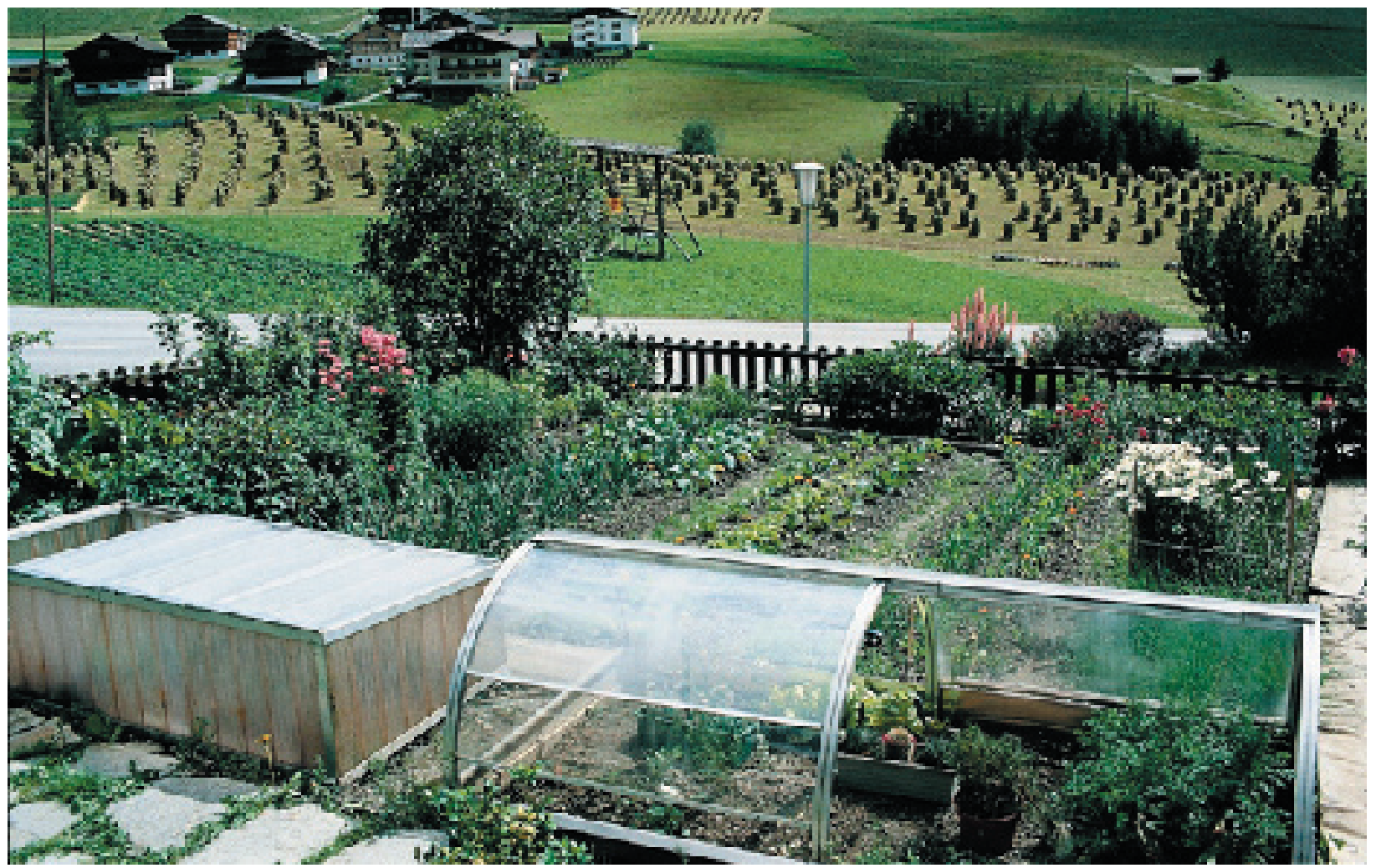

Above: Homegarden in Kartitsch (Eastern Tyrol, Austria) with little homemade green houses (Snow might fall here even in summer time). In the back: After hay harvest, when rain is expected and the hay is still not dry: Farmers form these small "figures" which protect the inner layers of the hay from getting wet (B.Vogl-Lukasser).

Below: Homegarden in Kals (Eastern Tyrol, Austria) (B.Vogl-Lukasser).

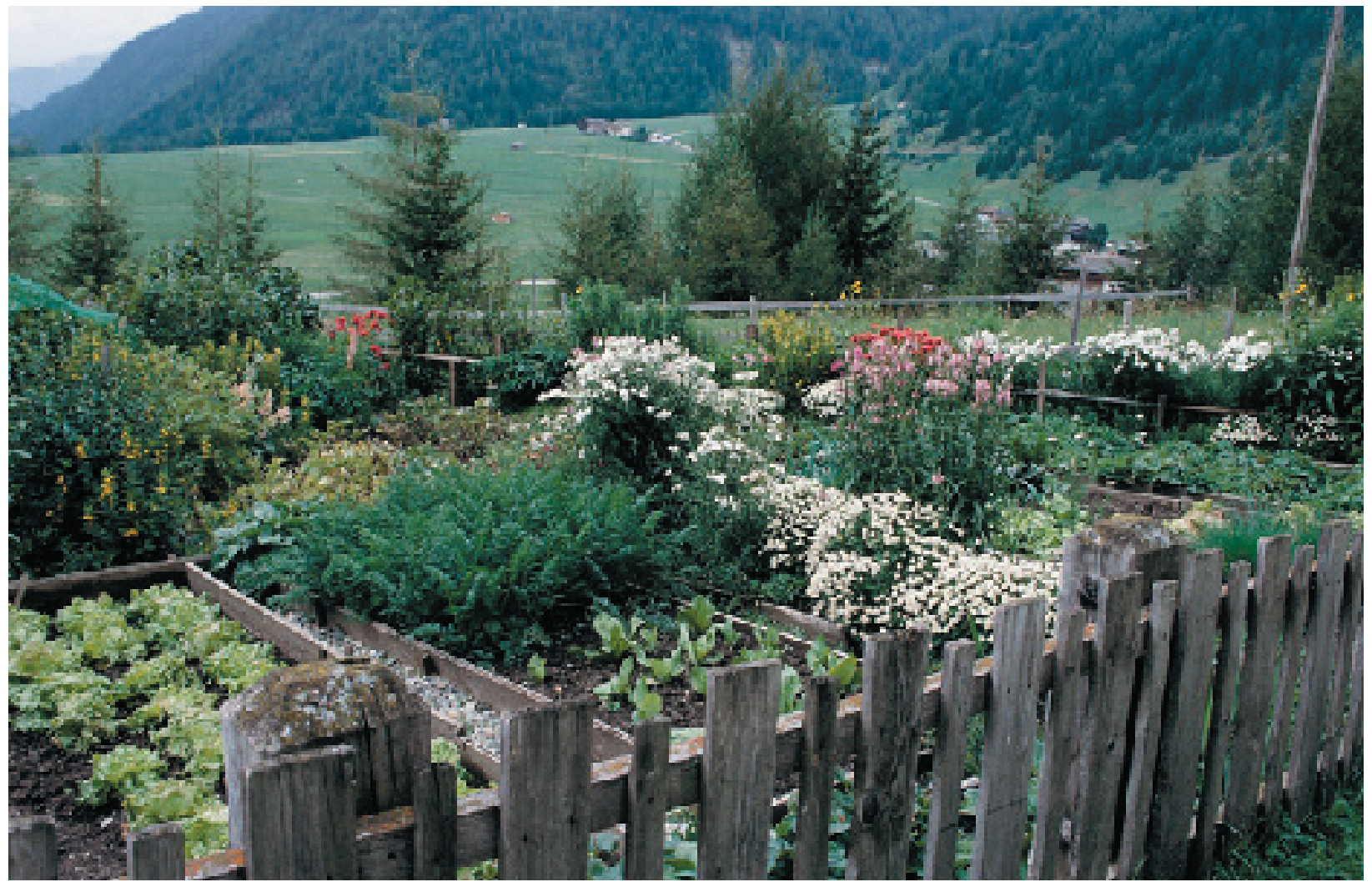




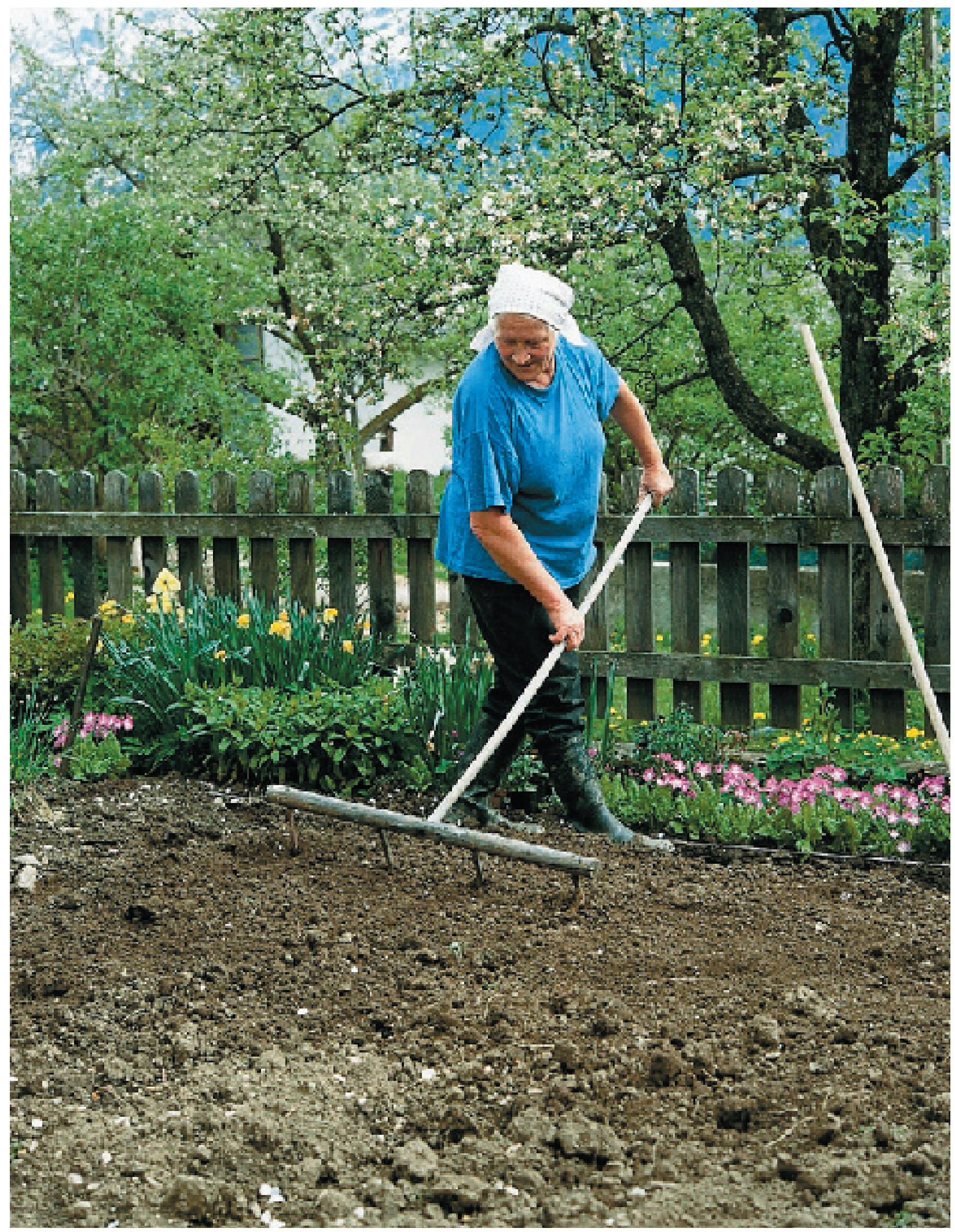

Above: Woman gardener in Gaimberg(Eastern Tyrol, Austria) with a traditional tool that is used to make the rows where later seeds are sown (B. Vogl-Lukasser). 


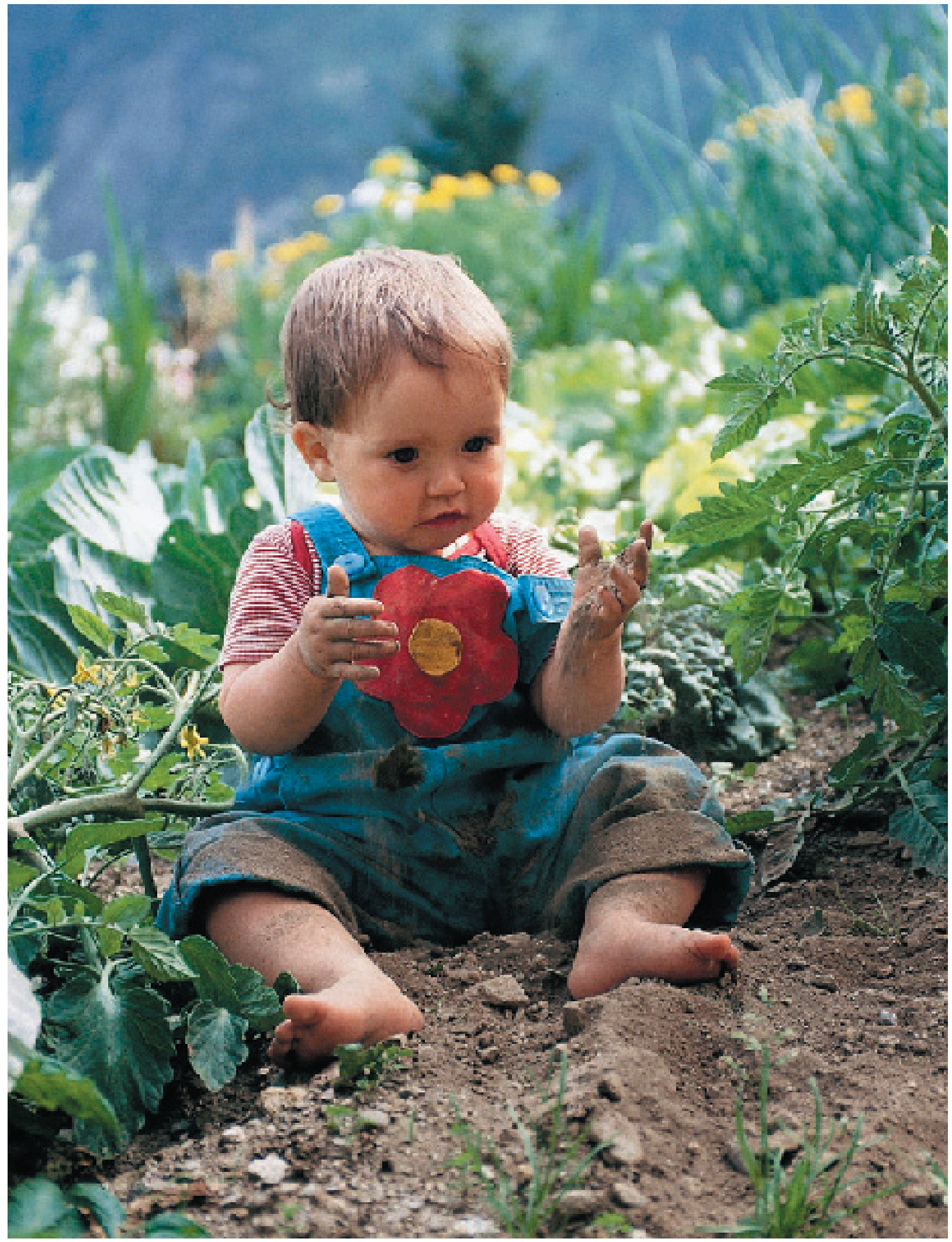

Above: Anna palying in the garden (Sillian, Eastern Tyrol, Austria) and learning about plant species, their uses and management from her mother and grandmother (B. Vogl-Lukasser) 